\title{
Detection of a Helicopter Input Pinion Bearing Fault Using Interstitial Envelope Analysis
}

\author{
Qiao Sun and Sally Anne McInerny ${ }^{\dagger}$ \\ Aerospace Engineering and Mechanics Department, The University of Alabama, \\ P.O. Box 870280, Tuscaloosa, AL 35487-0280, USA \\ William Hardman \\ Propulsion and Power Department, Naval Air Warfare Center Aircraft Division, \\ 22195 Elmer Rd., Bldg. 106, Patuxent River, MD 20670-1534, USA
}

(Received 29 November 2005; accepted 7 March 2006)

\begin{abstract}
Data recorded in an endurance test sequence during which the starboard pinion support bearing failed are analysed. Fault indicators, previously developed for this bearing, fail to detect its degradation until after the first chip light. Further analyses show that a cage fault is detectable in the earliest recorded dataset when the acceleration signal is bandpass filtered between the first and second GM frequencies, an interstitial frequency band. The starboard pinion bearing cage fault can also be seen in the earliest recorded data at the port main location, indicating that the distorted cage affects the power transmitted from the starboard main pinion to the main bevel gear and can, therefore, be detected on the other side of the gear box. Impact generated high frequency energy, as reflected in the kurtosis of the signal in a high frequency bandpass range, is not detectable until after the first chip light. The initial bearing fault, perhaps a cage distortion, may have led to the eventual spalling of the rollers. The results presented here can be used to develop prognostics that may safely permit extended operation of a main gearbox after the removal of a pinion with a spalled integral raceway.
\end{abstract}

${ }^{\dagger}$ Member of the International Institute of Acoustics and Vibration (IIAV)

\section{INTRODUCTION}

The U.S. Navy and U.S. Marine Corps rotary wing operators have long had a requirement to improve readiness through more effective maintenance. The major causes of Class A mishaps (those that result in a loss of aircraft and/or personnel) are engine and drive train failures. Accurate detection and diagnosis of developing mechanical faults is essential if maintenance costs and mechanically induced failures are to be reduced. ${ }^{1-5}$

The Navy began a comprehensive and continuing program to evaluate helicopter diagnostics, prognostic, and usage technologies in the early 1990s. The SH-60 was selected as the test vehicle because it offered the best availability of test assets, as well as, a high potential for eventual production support; there is a large fleet of SH-60 aircraft among the Navy, Army, and Coast Guard. Seeded fault tests performed on the SH-60 test bed in the Navy's Helicopter Transmission Test Facility (HTTF) were instrumental in the development of the Navy's Helicopter Integrated Diagnostic System (HIDS). ${ }^{1-5}$

One of the many seeded fault tests completed in the HTTF in the 1990s was the test of a spalled integral raceway bearing. ${ }^{1-3}$ Spalling of this raceway is one of the most common causes for the removal of the main gearbox on the SH-60. Figure 1 is a schematic of the H-60 main gearbox (MGB) showing the locations of the accelerometers on the MGB in the HTTF. A fleet rejected component, Fig. 2, was used for the spalled integral raceway seeded fault test. This component mates with the main bevel gear in the MGB as shown in Fig. 3; the shaft of the input pinion gear extends inboard of the gear, as shown, forming the inner race of the bearing.

The fleet rejected pinion in Fig. 2 was installed on the starboard side of the MGB for the seeded fault test. After completion of the test, the faulted component was removed from the gearbox. Removal of the bearing cage and rolling elements requires specialised tooling so that the entire gearbox has to be shipped back to the manufacturer. For this reason, the outer bearing elements - with which the spalled raceway had mated during the seeded fault test - were visually inspected using a mirror inserted inside the gearbox. There was no apparent damage to the bearing elements.

The HTTF was subsequently used for endurance testing of alternate source transmission system components for the UH-60 Blackhawk. ${ }^{6}$ As part of the ongoing development and testing of the HIDS algorithms, accelerometer data (not required for the endurance tests) were recorded throughout the endurance test series, albeit at irregular intervals. During the endurance test series, the gearbox chip light went on for the first time after 10,214 minutes (estimated) of elapsed runtime. Two hours after the first chip light, the bearing fault indicators detected a developing fault in the starboard pinion bearing. The chip light went on again at roughly 12,090 minutes and then again at 13,920 minutes. Six or seven chips were retrieved during the test cycles and were analysed; they were all, but one, of the same composition as the rolling elements in the degraded bearing. The other was gear steel. None of the fault indicators previously developed for this bearing showed a significant change until two hours (approximate runtime) after the first chip light came on. 